\title{
Presence of an expressed $\beta$-tubulin gene (TUBB) in the HLA class I region may provide the genetic basis for HLA-linked microtubule dysfunction
}

\author{
Armin Volz' ${ }^{1}$, Elisabeth Weiss ${ }^{2}$, John Trowsdale ${ }^{3}$, Andreas Ziegler ${ }^{1}$ \\ ${ }^{1}$ Institut für Experimentelle Onkologie und Transplantationsmedizin, Universitätsklinikum Rudolf Virchow, Freie Universität Berlin, \\ Berlin, Germany \\ ${ }^{2}$ Institut für Anthropologie und Humangenetik, Universität München, München, Germany \\ ${ }^{3}$ Human Immunogenetics Laboratory, ICRF Laboratories, London, UK
}

Received: 21 April 1993 / Revised: 7 June 1993

\begin{abstract}
An expressed $\beta$-tubulin gene (TUBB) has previously been localized to chromosome region 6pter-p21 in man. By using a panel of deletion mutant cell lines and radiation-reduced hybrids containing fragments of chromosome 6 , the TUBB locus could be mapped to the HLA class $I$ region at $6 \mathrm{p} 21.3$. A long range restriction map including TUBB and several HLA class I genes was then generated by rotating field gel electrophoresis. The results show that TUBB maps to a segment $170-370 \mathrm{~kb}$ telomeric of HLA-C. This location suggests that a mutation at the TUBB locus could be the cause for certain forms of HLAlinked microtubule dysfunction, including immotile cilia syndrome.
\end{abstract}

\section{Introduction}

Immotile cilia syndrome (ICS) is characterized by dysmotility or even complete immotility of spermatozoa and cilia in ciliated epithelia. It is inherited as an autosomal recessive trait; several loci are responsible for the different forms of the disease, depending on which structure of the cilia is altered (Afzelius et al. 1981; Palmblad et al. 1984). A common cause is attributable to structural alterations of the microtubules (Sturgess et al. 1980). The most frequent consequences include recurrent airway infections from early childhood on, and male sterility; females may be either fertile or infertile. Furthermore, a dramatic consequence in about $50 \%$ of the affected individuals is situs inversus (Mc Kusick 1987), in which case ICS is also referred to as Kartagener's syndrome.

Microtubules are required by most eukaryotic cells to perform essential functions, such as chromosome segregation in mitosis or cellular movement and the maintenance

Correspondence to: A. Ziegler, Institut für Experimentelle Onkologie und Transplantationsmedizin, Universitätsklinikum Rudolf Virchow, Freie Universität Berlin, Spandauer Damm 130, D-14050 Berlin, Germany of cell shape during interphase. They consist of $\alpha / \beta$ tubulin heterodimers, which are closely related polypeptides. Four classes of $\beta$-tubulins, characterized by their amino acid sequence, have been described; the class I isotype is the major constitutively expressed $\beta$-tubulin (Lopata and Cleveland 1987). The human $\beta$-tubulin class 1 gene, TUBB (originally named M40 or $h \beta 1$ ), has previously been mapped to chromosome region 6pter-p21 (FloydSmith et al. 1986). This region covers about $50 \mathrm{Mb}$ and encompasses the major histocompatibility (HLA) complex, localized at 6p21.3 (Ziegler et al. 1993). Bianchi and coworkers (1992) have recently presented evidence for the possible involvement of an HLA-linked gene in ICS. They described four children, with typical clinical symptoms of ICS, from two families. The affected individuals within a given family were HLA identical and were found to have abnormalities associated with microtubules in the cilia from the nasal mucosa. Based on the sib-pair test, Bianchi et al. (1992) have suggested linkage between this form of ICS and the TUBB locus. We demonstrate here that TUBB is indeed part of the HLA class I region, that it maps between HLA-C and HLA-E and that it may therefore be a candidate disease gene in certain forms of ICS.

\section{Materials and methods}

\section{Cell lines}

The deletion mutant cell lines employed were derived from the cloned Epstein-Barr-virus-infected $\mathrm{B}$ lymphoma line BJABB95.8.6 (HLA haplotypes A1, Cw4, B35; A2, C-, B13) (see Volz et al. 1992 for references). They exhibit interstitial deletions of the short arm at one of the two chromosomes 6 present.

The radiation hybrid cell lines used were derived from the human/hamster somatic cell hybrid R21B1, which contains one human chromosome 6 with an interstitial deletion of $6 \mathrm{q} 21-\mathrm{q} 25.2$ (Meese et al. 1992) and a Y chromosome (Ragoussis et al. 1991). R21B1 cells were irradiated, fused with the hamster cell lines A23N or W3GH, and cloned as described previously (Ragoussis et al. 1991). 


\section{DNA probes}

The following probes were employed: $p D A \alpha 13 b$ (specific for HLA-DP $\beta$; Trowsdale et al. 1985); p11-13 (specific for HLADP $\alpha$; Trowsdale et al. 1984); p6 (3' flanking sequence, specific for HLA-B; Ragoussis et al. 1989); LG2-E2 (3' untranslated sequence, specific for HLA-E; Ulbrecht et al. 1992); p259 (SalI-PstI fragment, contains the $5^{\prime}$ untranslated sequence and the first exon of HLA-H; unpublished); HLA-A2 (3’ flanking sequence, specific for HLA-A; Ragoussis et al. 1989); 21ß3'UT specific for TUBB; Lee et al. 1983).

\section{Rotating field electrophoresis and Southern blotting}

Agarose blocks were prepared from the cell lines BM19.7 and R21B 1. Aliquots containing $5 \times 10^{5}$ cells were digested overnight with 30 units of various rare cutting restriction enzymes according to the instructions of the manufacturer. Fragments were separated by rotating field gel electrophoresis (ROFE) (Ziegler and Volz 1992) using the following parameters: duration $36 \mathrm{~h}$, interval 10$110 \mathrm{~s}$ linear, angle $125^{\circ}-100^{\circ}$ linear, field strength $5.7-6.7 \mathrm{~V} / \mathrm{cm}$ linear, temperature $13^{\circ} \mathrm{C}$, agarose $0.9 \%$ Seakem GTG in $0.025 \mathrm{M}$ TBE. After $10 \mathrm{~min} \mathrm{HCl}$ depurination, DNA was alkaline-transferred to a Genescreen plus membrane (Dupont/NEN) and UVlinked. Probes were labelled with ${ }^{32} \mathbf{P}$ using the Megaprime kit (Amersham). Southern hybridization was performed as described previously (Church and Gilbert 1984). Bands were detected by autoradiography using Kodak XAR film. After autoradiography, membranes were stripped with $0.1 \times \mathrm{SSC}, 1 \%$ SDS at $99^{\circ} \mathrm{C}$ for 10 min. Successful stripping was tested by a $72 \mathrm{~h}$ exposure prior to the next hybridization.

\section{Polymerase chain reaction}

About $50 \mathrm{ng}$ genomic DNA was used per $10 \mu \mathrm{l}$ reaction with 1.5 $\mathrm{m} M \mathrm{MgCl}_{2}, 200 \mu M \mathrm{dNTPs}$ and $0.1 \mu M$ of each primer. Amplifications were carried out in 37 cycles $\left(94^{\circ} \mathrm{C}\right.$ for $1 \mathrm{~min}, 56^{\circ} \mathrm{C}$ for $1.5 \mathrm{~min}, 72^{\circ} \mathrm{C}$ for $1.5 \mathrm{~min}$ ) on a DNA Thermal Cycler (Perkin Elmer Cetus). The primers used (no. 4283: $5^{\prime}$-TGCCTCACGAACATACATAA-3' and no.4284: 5'-TCGACTGGCTCCTGACTACGA-3) were specific for a CA dinucleotide repeat in the vicinity of HLA-F; they were a gift from Dr. J.R. Gruen (Yale University, New Haven)

\section{Results}

Physical mapping of the TUBB gene was accomplished by a three step process. As a first step, a panel of immunoselected chromosome 6 deletion mutant cell lines was employed. This panel defines several mapping intervals on $6 \mathrm{p}$ for polymorphic loci. A 9.8-kb ApaI and a 7.3-kb AvaI restriction fragment, both belonging to the chromosome 6 carrying the HLA-A2 haplotype of the parental cell line BJAB-B95.8.6, were detected after blotting and hybridization with the TUBB probe only in cell lines with no interstitial deletion of this chromosome. BM2.2.3, a subclone of BM2.2, exhibits the smallest deletion and therefore narrows the interval containing TUBB to $6 \mathrm{p} 23.05-\mathrm{p} 21.3$. The centromeric breakpoint in this mutant is between the TNF loci and HLA-B (Ragoussis 1988), showing that TUBB maps telomeric of TNFB.

A more precise regional localization was then accomplished by employing a panel of irradiation-fusion-genetransfer (IFGT) hybrids. This panel consists of hamster cell lines containing different fragments of human chromosome 6 . Of 40 IFGT hybrids tested either by hybridization or by the polymerase chain reaction (PCR) with locus-specific probes and oligonucleotides respectively, 9 contained various HLA genes, but only 7 were found to harbour class I sequences and 6 hybrids gave reactivity with the TUBB probe. Some 31 IFGT cell lines were negative with these probes, although they contained several other chromosome 6 loci (results not shown). Of over 100 markers analysed on the hybrid panel (results not shown), only HLA-E gave complete concordance with TUBB (Table 1). These data confirmed and extended the results obtained by the deletion mutants, suggesting that the TUBB locus mapped in the vicinity of HLA-E in 6p21.3.

Precise localization of TUBB in the HLA complex was obtained by ROFE: the information from all single and double digests of BM19.7 DNA and the various hybridizations could be compiled into a long range restriction map of the HLA-A2, C-, B13 haplotype (Fig. 1). The results observed with the TUBB probe were more difficult to interpret than those obtained, for example, with the HLA-A probe, because of cross hybridizing $\beta$-tubulin pseudogenes on chromosomes 8 and 13 (Floyd-Smith et al. 1986). DNA from the monosomy 6 cell line BM 19.7 was employed to avoid restriction fragment length polymorphisms. The rare cutting restriction enzymes Not $\mathrm{I}$, $N r u \mathrm{I}$ and $M l u \mathrm{I}$ were employed for digestions and, after separation with ROFE, restriction fragments were detected by sequential Southern hybridization using specific probes (Fig.2).
Table 1. Assignment of HLA loci and TUBB to individual radiation hybrids

\begin{tabular}{|c|c|c|c|c|c|c|c|c|}
\hline \multirow[t]{2}{*}{ Cell line } & \multicolumn{7}{|c|}{ HLA locus } & \multirow[t]{2}{*}{ TUBB } \\
\hline & DPB & DPA & B & $\mathrm{E}$ & A & $\mathbf{H}$ & $\mathbf{F}$ & \\
\hline $4 \mathrm{G} 6$ & + & + & + & + & + & + & + & + \\
\hline $5 \mathrm{P} 9.6$ & - & - & + & + & + & + & + & + \\
\hline $4 V 6$ & - & - & + & + & + & + & + & + \\
\hline $4 \mathrm{H} 2$ & - & - & - & + & + & + & + & + \\
\hline $5 \times 4$ & - & - & - & + & + & + & + & + \\
\hline $4 J 4$ & - & - & + & - & - & + & - & - \\
\hline $4 \mathrm{H} 6$ & + & + & - & + & - & - & - & + \\
\hline $4 \mathrm{~L} 1$ & + & + & - & - & - & - & - & - \\
\hline $5 \mathrm{TI}$ & + & + & - & - & - & - & - & - \\
\hline $\begin{array}{l}\text { Other hybrids } \\
\quad(n=31)\end{array}$ & - & - & - & - & - & - & - & - \\
\hline
\end{tabular}




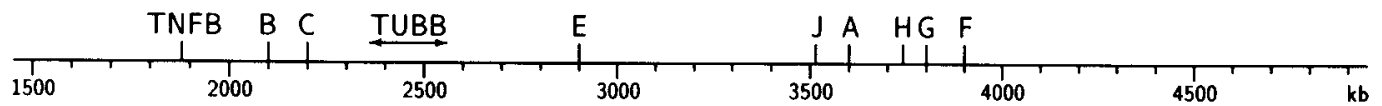

Nru $\times \mathrm{Mlu} \longrightarrow$ Not $\times \mathrm{Mlu} \longrightarrow$

Fig. 1. Restriction map of the HLA class I region from the monosomy 6 mutant cell line BM19.7 (HLA-A2,C-,B13 haplotype)

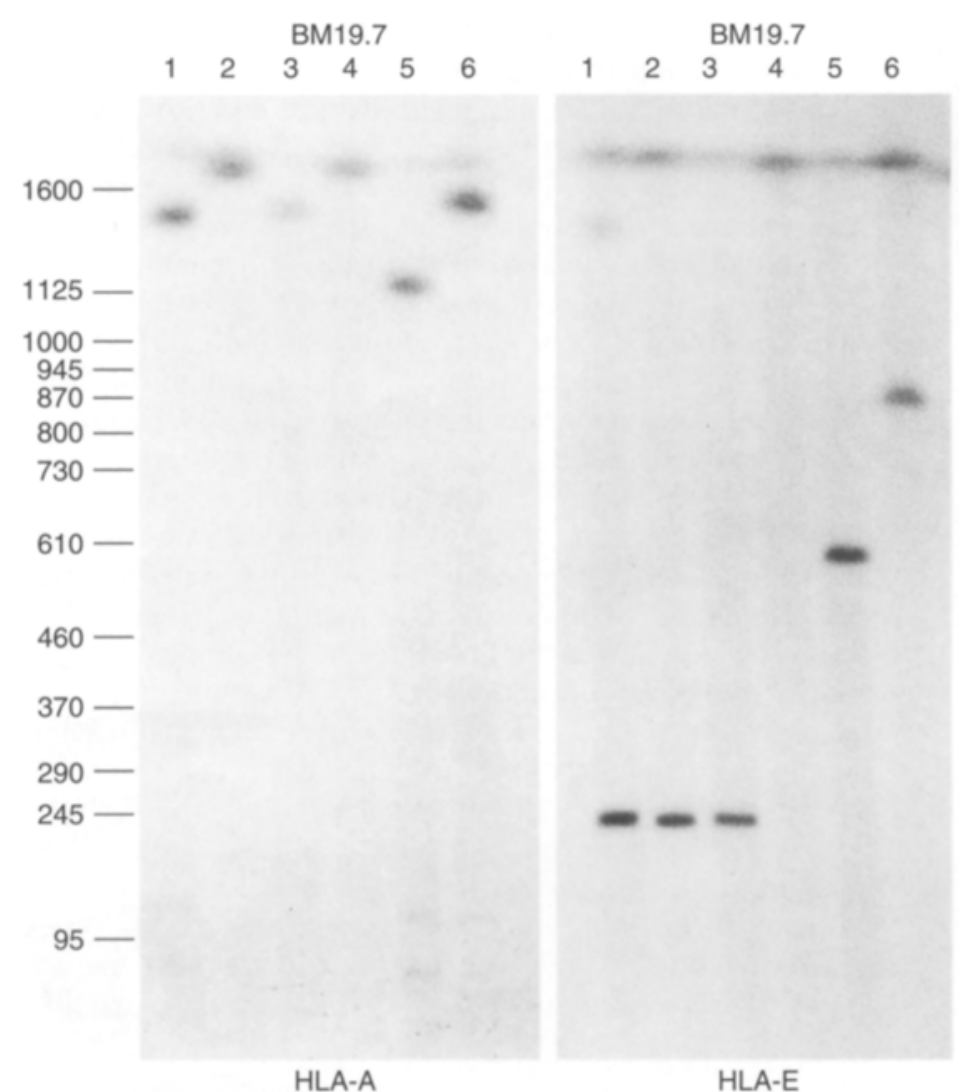

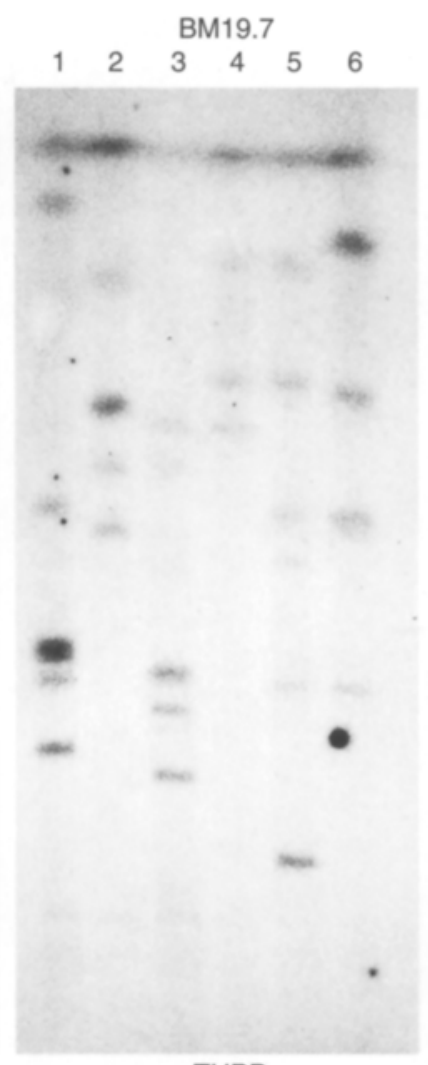

TUBB

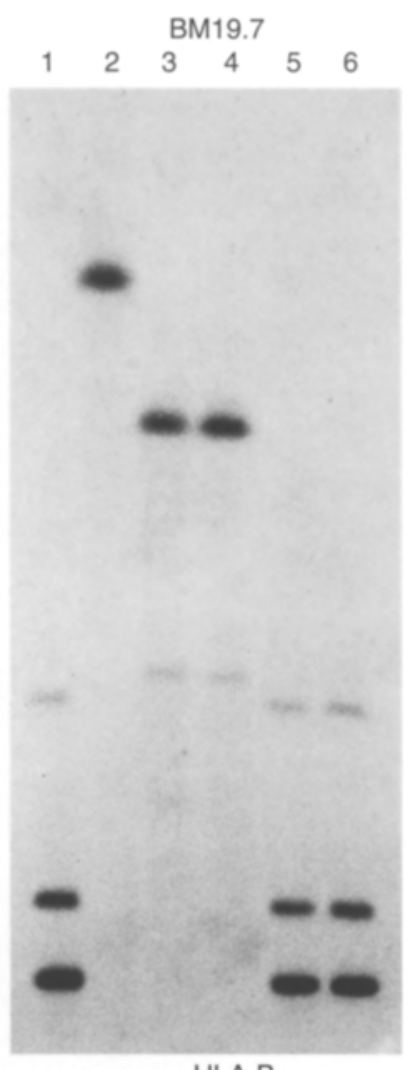

HLA-B
Fig. 2. Sequential southern hybridizations after ROFE with genomic DNA of the cell line BM19.7. DNA was digested with: lanes 1, MluI × NotI; lanes 2, Not I; lanes 3, Not I $\times$ NruI; lanes 4, $N r u \mathrm{I}$; lanes $5, N r u \mathrm{I} \times M l u \mathrm{I}$; lanes 6, MluI; fragment lengths in $\mathrm{kb}$

The HLA-A probe revealed long, largely overlapping $N o t \mathrm{I}, N r u \mathrm{I}$ and $M l u \mathrm{I}$ fragments characteristic of the HLAA2, B13 haplotype (Ragoussis et al. 1989). HLA-E was not present on any of the fragments detectable by the HLA-A probe, except on a large $\mathrm{NruI}$ fragment that contained HLA-A,-J,-H,-G and F (results not shown) (Gruen et al. 1992). This fragment showed overlapping with an 880-kb MluI fragment and gave rise to a $590-\mathrm{kb}$ fragment after double digestion. Both the $880-\mathrm{kb}$ and the $590-\mathrm{kb}$ bands contained HLA-E. The IFGT-hybrid mapping results had indicated that TUBB might be located close to HLA-E. However, the 590-kb MluI $\times$ NruI double digestion product did not hybridize to TUBB, showing that, if this gene was part of the $880-\mathrm{kb} M l u I$ fragment, then it mapped centromeric of HLA-E in the other fragment generated by the double digestion, with a predicted maximal length of $290 \mathrm{~kb}$. The only fragment with this maximal length in the double digest had a length of $200 \mathrm{~kb}$ and was not present in the MluI or NruI single digests. It hybridized to the TUBB probe but not to any other HLA 
class I gene probe employed here. The HLA-B and HLAC loci were found on a Not $\mathrm{I}$ fragment with a length of $1160-\mathrm{kb}$ and on an 800-kb long NruI fragment. Both these fragments also hybridized to the TUBB probe and a double digest with these enzymes gave the expected (Ragoussis et al. 1989) unchanged NruI pattern with HLA-B and with TUBB. The known distance between HLA-C and HLA-E (Gruen et al. 1992; Bronson et al. 1991) implied that the TUBB gene was on a $400-\mathrm{kb}$ Not $\mathrm{I} \times M l u \mathrm{I}$ double digestion fragment. This was indeed the case, and demonstrated, when combined with results from all other digestions, that, in the HLA-A2,B13 haplotype present within BM19.7 cells, TUBB maps between HLA-C and HLA-E, $170-370-\mathrm{kb}$ telomeric of HLA-C and $320-520-\mathrm{kb}$ centromeric of HLA-E.

Additional experiments with the R21B1 hybrid cells confirmed these observations: the loss of all human chromosomes, except the $\mathrm{Y}$ and the partially deleted single chromosome 6 in this hybrid cell line, gave a simplified hybridization pattern with TUBB. A comparison with BM19.7 using the TUBB probe showed that the NruI fragment predicted to contain TUBB in the HLA-A2, B13 haplotype of BM19.7 was the only one observed in R21B1. An analogous situation was observed for $N r u \mathrm{I} \times M l u \mathrm{I}$ double digestions, although the $M l u \mathrm{I}$ single digest fragment of BM19.7 hybridizing with TUBB and with HLA$E$ was $400 \mathrm{~kb}$ longer than the equivalent R21B1 fragment. The long Not I fragment containing HLA-B,C and TUBB in BM19.7 cells also occurred in R21B1, further confirming the HLA-A2, C-, B13 restriction map (Fig. 1).

\section{Discussion}

All the results from the monosomy 6 mutant and the $\mathrm{R} 21 \mathrm{~B} 1$ human/hamster hybrid are in concordance and lead to the conclusion that TUBB is part of the HLA complex and that it maps between HLA-C and HLA-E. No locus unrelated to histocompatibility antigens has been mapped to the HLA class I region to date, apart from the gene for a putative G-protein (Denizot et al. 1992). Since this gene is localized to a $210-\mathrm{kb}$ Not I fragment that also hybridizes with an HLA-E probe (determined to be 220 $\mathrm{kb}$ long in this study), it must map telomeric of TUBB.

Our data are compatible with the involvement of the TUBB gene in those forms of HLA-linked ICS in which microtubular function is impaired. Bianchi and coworkers (1992) have reported that all four children with ICS from the two investigated families expressed HLA-DR7 and HLA-DQ2, either in a heterozygous or homozygous manner. Since the distance between HLA-DRA and TUBB must be about $1500 \mathrm{~kb}$, we anticipate that linkage disequilibrium within the HLA complex might account for the observed association. In one family, HLA-A29, C-, and B44 were also part of the DR7, DQ2-haplotype carried by the diseased children; the other haplotype was in both cases identical (HLA-A11, Cw4, B35, DR1, DQ1). In the other family, the two patients were HLA-identical (A26, Cw6, B13, DR7, DQ2; A30, Cw6, B13, DR7, DQ2). Both HLA-B13 and HLA-B44 are in strong linkage disequilibrium with HLA-DR7, and the same has been observed for HLA-A30 and B13. Extended haplotypes involving other HLA class I and class II alleles, such as HLA-A1, Cw7, B8 and DR3, have been known for many years (Tiwari and Teraski 1985). The significant association of ICS with the HLA-DR7 antigen observed by Bianchi and coworkers (1992) is thus conceivably the consequence of haplotype conservation by linkage disequilibrium.

Since the mouse class $1 \beta$-tubulin gene (M $\beta 5)$ resembles TUBB (Lopata and Cleveland 1987), the apparently ubiquitous expression of the murine gene suggests that this may also be the case for TUBB. Thus, certain forms of ICS are consistent with a mutation in TUBB. Although it has been reported that different tubulin- $\beta$ chains are coassembled in functionally distinct microtubules in vivo (Lewis et al. 1987), it has been speculated that specialized "microtubule-associated proteins" might need the "right" $\alpha / \beta$ tubulin for interaction. Additionally, the expression of $\beta$-tubulin isotypes is tissue specific and therefore substitution of the TUBB product by other isotypes may fail. To our knowledge, mutations affecting the TUBB locus have not been described to date. The reason for this could be that inactivation of the TUBB gene may be lethal because of its essential function in mitotic chromosome segregation in the embryo. Therefore, the presence of TUBB in the HLA region might be one of the factors responsible for the prevention of heritable losses of chromosomal material from the HLA complex. It will be interesting to investigate the conservation of this localization in different species, in addition to searching for mutated TUBB genes in individuals with HLA-linked forms of ICS.

Acknowledgements. We should like to express our gratitude to Dr. Barbara Uchanska-Ziegler for providing the cell lines, and Mrs. Waltraut Bangel for help with gel electrophoresis.

\section{References}

Afzelius BA (1981) Genetical and ultrastructural aspects of the immotile-cilia syndrome. Am J Hum Genet 33:852-864

Bianchi E, Savasta S, Calligaro A, Beluffi G, Poggi P, Tinelli M, Mevio E, Martinetti M (1992) HLA haplotype segregation and ultrastructural study in familial immotile-cilia syndrome. Hum Genet $89: 270-274$

Bronson SK, Pei J, Taillon-Miller D, Chorney MJ, Geraghty DE, Chaplin DD (1991) Isolation and characterization of yeast artificial chromosome clones linking HLA-B and HLA-C loci. Proc Natl Acad Sci USA 88:1676-1680

Church GM, Gilbert W (1984) Genomic sequencing. Proc Natl Acad Sci USA 81: 1991-1995

Denizot F, Mattei MG, Vernet C, Pontarotti P, Chimini G (1992) YAC- assisted cloning of a putative G-protein mapping to the MHC class I region. Genomics $14: 857-862$

Floyd-Smith G, De Martinville B, Francke U (1986) An expressed $\beta$-tubulin gene, TUBB, is located on the short arm of human chromosome 6 and two related sequences are dispersed on chromosomes 8 and 13. Exp Cell Res 163:539-548

Gruen JR, Goei VL, Summers KM, Capossela A, Powell L, Halliday J, Zoghbi H, Shukla H, Weissman S (1992) Physical and genetic mapping of the telomeric major histocompatibility complex region in man and relevance to the primary hemochromatosis gene (HFE). Genomics 14:232-240

Lee MGS, Lewis SA, Wilde CD, Cowan NJ (1983) Evolutionary history of a multigene family: an expressed human $\beta$-tubulin gene and three processed pseudogenes. Cell 33:477-487 
Lewis SA, Gu W, Cowan NJ (1987) Free intermingling of mammalian $\beta$-tubulin isotypes among functionally distinct microtubules. Cell 49:539-548

Lopata MA, Cleveland DW (1987) In vivo microtubules are copolymers of available $\beta$-tubulin isotypes: localization of each of six vertebrate $\beta$-tubulin isotypes using polyclonal antibodies elicited by synthetic peptide antigens. J Cell Biol 105:17071720

McKusick VA (1987) Mendelian inheritance in man, Johns Hopkins University Press, Baltimore, 10th ed. (1992) document nr. 242650

Meese EU, Witkowski CM, Zoghbi HY, Stanbridge EJ, Meltzer PS, Trent JM (1992) Development and utilization of a somatic cell hybrid mapping panel to assign NotI linking probes to the long arm of human chromosome 6. Genomics 12:542-548

Palmblad J, Mossberg B, Afzelius BA (1984) Ultrastructural, cellular and clinical features of the immotile-cilia syndrome. Annu Rev Med 12:481-492

Ragoussis J (1988) Ph.D. Thesis, Physikalische Kartierung des Haupthistokompatibilitätskomplexes beim Menschen, Fakultät für Chemie und Pharmazie, Universität Tübingen

Ragoussis J, Bloemer K, Pohla H, Messer G, Weiss EH, Ziegler A (1989) A physical map including a new class I gene (cda12) of the human major histocompatibility complex (A2/B13 haplotype) derived form a monosomy 6 mutant cell line. Genomics 4:301-308

Ragoussis J, Jones TA, Sheer D, Shrimpton AE, Goodfellow PN, Trowsdale J, Ziegler A (1991) Isolation of probes specific to human chromosomal region $6 \mathrm{p} 21$ from immunoselected irradiation-fusion gene transfer hybrids. Genomics 10:598-607
Sturgess JM, Chao J, Turner JAP (1980) Transposition of ciliary microtubules. Another cause of impaired motility. $\mathrm{N}$ Engl $\mathrm{J}$ Med 303:318-322

Tiwari JL, Terasaki PI (1985) HLA and disease associations. Springer, New York Berlin Heidelberg

Trowsdale J, Kelly A, Lee J, Carson S, Austin P, Travers P (1984) Linkage map of two HLA-SB beta and two HLA-SB alpharelated genes: an intron in one of the $\mathrm{SB}$ beta genes contains a processed pseudogene. Cell 38:241-249

Trowsdale J, Young JA, Kelly AP, Austin PJ, Carson S, Meunier $\mathrm{H}$, So A, Erlich HA, Spielman RS, Bodmer J, Bodmer WF (1985) Structure, sequence and polymorphism in the HLA-D region. Immunol Rev $85: 5-43$

Ulbrecht M, Honka T, Person S, Johnson JP, Weiss EH (1992) The HLA-E gene encodes two differentially regulated transcripts and a cell surface protein. J Immunol 149:2945-2953

Volz A, Fonatsch C, Ziegler A (1992) Regional mapping of the gene for autosomal dominant spinocerebellar ataxia (SCA1) by localizing the closely linked D6S89 locus to 6p24.2-p23.05. Cytogenet Cell Genet 60:37-39

Ziegler A, Volz A (1992) Rotating field gel electrophoresis (ROFE). In: Burmeister M, Ulanovsky L (eds) Methods in molecular biology, vol 12. Pulsed field gel electrophoresis. Humana, Totowa, NJ, pp 63-72

Ziegler A, Campbell R, Trent J, Cann H (1993) Report of the committee on the genetic constitution of chromosome 6. Genome Priority Reports 1:269-294 